\title{
ENCONTRABILIDADE DA INFORMAÇÃO EM REPOSITÓRIOS DE DADOS: UMA ANÁLISE DO DATAONE
}

\author{
THE FINDABILITY OF INFORMATION IN DATA \\ REPOSITORIES: AN ANALYSIS OF DATAONE
}

\author{
Fernanda Alves Sancheza \\ Fernando Luiz Vechiato ${ }^{b}$ \\ Silvana Aparecida Borsetti Gregorio Vidottic
}

\begin{abstract}
RESUMO
Introdução: a importância da disseminação de dados de pesquisa vem sendo cada vez mais debatida pela comunidade científica no contexto da Ciência Aberta, principalmente para maximizar o uso e o reuso dos dados provenientes de pesquisas científicas. Os Repositórios de Dados visam o armazenamento, a organização, a disseminação, a recuperação e a preservação de dados de pesquisa, potencializando a comunicação e a colaboração científica. Os estudos do campo da Ciência da Informação, em especial a Encontrabilidade da Informação, trazem contribuições significativas para o projeto e para a implementação de Repositórios de Dados. Objetivos: analisar o repositório de dados DataONE sob a ótica da Encontrabilidade da Informação. Metodologia: utilizou-se a técnica de observação com apoio do instrumento de avaliação checklist, que permite a análise de ambientes informacionais a partir dos atributos de Encontrabilidade da Informação. Resultados: como aspectos positivos destacam-se a utilização de padrão de metadados específico para a comunidade das Ciências da Terra, a Ecological Metadata Language (EML), e o atributo de Responsividade. Como aspecto negativo, nota-se a ausência de recursos de Acessibilidade Digital. Conclusão: conclui-se que, de modo geral, o DataONE contempla os principais atributos de Encontrabilidade da Informação, o que facilita a interação e a encontrabilidade dos dados e da informação pelos sujeitos informacionais.
\end{abstract}

\footnotetext{
a Mestranda em Ciência da Informação pela Universidade Estadual Paulista (PPGCI-UNESP). E-mail: feersanchez@gmail.com

b Doutor em Ciência da Informação pela Universidade Estadual Paulista (PPGCI-UNESP). Professor do Departamento de Ciência da Informação da Universidade Federal do Rio Grande do Norte (UFRN). Professor no Programa de Pós-Graduação em Ciência da Informação (PPGCI-UNESP). E-mail: vechiato2008@gmail.com

c Doutora em Educação pela Faculdade de Filosofia e Ciências da UNESP. Professora do Departamento de Ciência da Informação e Pós-Graduação em Ciência da Informação (PPGCI-UNESP). E-mail: svidotti@gmail.com
} 
Descritores: Encontrabilidade da Informação. Repositórios de Dados. Dados de Pesquisa. DataONE.

\section{INTRODUÇÃO}

As últimas décadas foram conduzidas por evoluções relacionadas às Tecnologias de Informação e Comunicação (TIC), além da explosão de dados e informações gerados no ambiente Web. Em paralelo, a Ciência da Informação $(\mathrm{Cl})$ busca atender as necessidades informacionais da sociedade, sendo responsável por estudos que permeiam a organização, a representação, a disseminação, a recuperação, o uso e a apropriação da informação pelos sujeitos nos mais diversos ambientes informacionais.

Atualmente o debate sobre a necessidade de partilha de dados na comunidade científica vem aumentando, especialmente no contexto da Ciência Aberta, visto que a maioria das pesquisas são financiadas com recursos públicos e há a necessidade de divulgação dos dados de pesquisa utilizados durante as pesquisas, visando garantir transparência, geração de novas hipóteses e ideias, além de evitar a duplicação de dados.

Nessa perspectiva, organizações governamentais e instituições de ensino e pesquisa visam a importância de um ambiente informacional digital que atenda às necessidades relacionadas a disseminação dos dados de pesquisa. Assim, nascem os Repositórios de Dados, ambientes informacionais digitais que buscam armazenar, organizar, representar, prover acesso, disseminar e preservar dados oriundos de pesquisas científicas.

A Encontrabilidade da Informação (El), por sua vez, é um estudo que visa atender as necessidades informacionais dos sujeitos em ambientes informacionais, contribuindo para que as informações disponíveis sejam encontradas rapidamente e com o mínimo de esforço possível. Os aspectos teóricos e práticos da $\mathrm{El}$ ainda são recentes dentro do cenário da $\mathrm{Cl}$ e tem como um dos de seus focos a apropriação da informação, um processo informacional posterior aos processos de busca e recuperação da informação em que o sujeito informacional tem a possibilidade de gerar conhecimento a 
partir da informação que encontrou com base em suas necessidades informacionais.

Neste artigo, foram abordados os Repositórios de Dados pela necessidade de potencializar a cultura de partilha e de reuso de dados de pesquisa. Como objetivo buscou-se analisar o repositório de dados DataONE para verificar a aplicabilidade dos atributos da Encontrabilidade da Informação nesse ambiente.

Este trabalho possui relevância acadêmico-científica, considerando a emergência dos repositórios de dados, ambientes que trazem funcionalidades específicas, e a possibilidade de avaliá-los à luz dos atributos de El, o que pode contribuir para os pesquisadores que utilizam esses ambientes no âmbito de suas pesquisas, o que também caracteriza sua relevância social.

\section{PROCEDIMENTO METODOLÓGICOS}

A presente pesquisa busca desenvolver uma análise descritiva e qualitativa que ocorre em dois momentos. Em um primeiro momento foi realizada pesquisa bibliográfica a partir do levantamento bibliográfico em bases de dados nacionais e internacionais a fim de contextualizar os temas Encontrabilidade da Informação e Repositórios de Dados, com vistas à elaboração do referencial teórico.

Posteriormente, foi selecionado aleatoriamente para análise o repositório de dados DataONE, identificado a partir de um levantamento no diretório Re3data - Registry Of Research Data Repositories'. Para Sayão e Sales (2015), esse tipo de diretório é uma ferramenta importante para que se possa indicar os repositórios mais adequados para abrigar os dados de pesquisa de forma fácil, assim, aumentando a visibilidade do repositório armazenado ali e dos resultados das pesquisas. O DataONE tem como objetivo armazenar, organizar e divulgar dados relacionados com a ciência ambiental da Terra.

A análise ocorreu no mês de agosto do ano de 2017 a partir da técnica

\footnotetext{
1 http://www.re3data.org
} 
de observação. Como instrumento de avaliação foi utilizado o "Checklist para avaliação de ambientes informacionais híbridos" elaborado por Vechiato, Oliveira e Vidotti (2016) e adaptado neste texto, que auxiliou na avaliação de possíveis problemas relacionados a Encontrabilidade da Informação no Repositório de Dados - DataONE.

\section{REPOSITÓRIO DE DADOS}

Atualmente, no contexto da Ciência Aberta, a comunidade científica vem debatendo sobre a necessidade de partilha dos dados de pesquisa, principalmente no âmbito das pesquisas financiadas com recursos públicos. Nesse sentido, cresce um movimento denominado "Data Sharing". (SALINAS; MARTÍN; GUTIERRÉZ, 2014).

Podemos associar o movimento citado com o "Open Acess" que surgiu em 2002 como a primeira grande iniciativa internacional sobre o acesso aberto graças à declaração conhecida como Budapest Open Access Initiative que, por sua vez, impulsionou o acesso aberto às produções científicas.

Com a explosão na geração de dados acontecendo demasiadamente, cresce a demanda pela criação de ambientes informacionais digitais como os Bancos de Dados ou Repositórios de Dados dedicados a: armazenar, organizar, descrever e disseminar dados de pesquisa (SALINAS; MARTíN; GUTIERRÉZ, 2014). Em complemento aos autores, Monteiro e Sant'Ana (2016) acrescentam que Repositórios de Dados possibilitam o processamento, gerenciamento, acesso dos dados, incluindo métodos da curadoria digital que se preocupam com o ciclo de vida dos dados.

A implementação desse tipo de ambiente contribui com os pesquisadores para a partilha e a reutilização de conjuntos de dados brutos de suas pesquisas, impulsionando a pesquisa em grande escala, além de acelerar o movimento de comunicação científica (KIM; ZHANG, 2015). Além disso, são mais apropriados para que os dados sejam preservados, recuperados, acessados e citados por outros pesquisadores, atingindo escala mundial em relação à visibilidade de pesquisas enriquecidas por estudos comparativos e 
com análises mais sofisticadas (KIM; ZHANG, 2015; SAYÃO; SALES, 2015).

Dentro desse contexto, são potencializadas as chances de surtir efeitos inputs para novas hipóteses de pesquisa, além da economia de dinheiro público evitando a duplicação de dados de pesquisa e possibilidades de novas descobertas de pesquisa (MONTEIRO; SANT'ANA, 2016).

Sayão e Sales (2015) destacam vantagens em relação a utilização dos Repositórios de Dados, exemplificadas na Figura 1 que segue:

Figura 1 - Vantagens em utilizar os Repositórios de Dados

\begin{tabular}{|c|c|}
\hline Vantagem & Descrição \\
\hline Qualidade & $\begin{array}{l}\text { Assegura que os dados estejam em } \\
\text { conformidade com os padrões de qualidade; }\end{array}$ \\
\hline Preservação Digital & $\begin{array}{c}\text { Garante a preservação digital de longo prazo } \\
\text { dos dados; }\end{array}$ \\
\hline Segurança & Mantém os dados em ambiente seguro; \\
\hline Backup & Providência backups regulares dos dados; \\
\hline Descoberta & $\begin{array}{l}\text { Viabiliza a descoberta online dos dados via } \\
\text { catálogo de dados; }\end{array}$ \\
\hline Formatos Conhecidos & Acesso aos dados em formatos populares; \\
\hline Direitos & $\begin{array}{l}\text { Mantém acordo de licenciamento que } \\
\text { reconhece os direitos sobre os dados; }\end{array}$ \\
\hline Citação & $\begin{array}{l}\text { Disponibiliza mecanismos de citação que } \\
\text { reconhece a autoria dos dados; }\end{array}$ \\
\hline Reuso & $\begin{array}{c}\text { Promove o uso e reuso de dados para } \\
\text { muitos salários; }\end{array}$ \\
\hline Gestão de Acesso & $\begin{array}{c}\text { Gerencia o acesso aos dados e as consultas } \\
\text { dos usuários em nome do proprietário dos } \\
\text { dados. }\end{array}$ \\
\hline
\end{tabular}

Fonte: (SAYÃO; SALES, 2015, p. 55).

Uma das maiores vantagens dos repositórios está ligada a possibilidade de inserção de diferentes tipologias e formatos de dados de pesquisa como: textual, numérico, imagens, linguagem de software e etc. A contraponto, existe a preocupação com a preservação dos dados gerados em formatos diferentes de software e hardware e que podem vir a sofrer mudanças em pouco espaço de tempo. Sendo assim, fazer uso de formatos de dados padronizados e abertos assegura o uso e o reuso a longo prazo. (SAYÃO; SALES, 2015).

Tolle, Tansley e Hey (2011, p. 24) acreditam em "[...] unificar todos os dados de pesquisa e toda a literatura para criar um mundo em que os dados e a literatura possam interagir" por meio da Internet. Fica claro que esta contribui com a velocidade com que a informação é distribuída, mas são necessárias 
ferramentas que auxiliem na organização desse processo.

Desse modo, Repositórios de Dados são ótimos para exemplificar o que os autores defendem, pois neles armazenam-se desde os dados brutos desenvolvidos durante a pesquisa, até a literatura produzida a partir dos resultados que foram obtidos. Assim, os "[...] dados podem ser combinados, recombinados e usados por áreas multidisciplinares, ser unificados, integrados e interoperados em rede" (MONTEIRO; SANT'ANA, 2016, p. 655).

A Interoperabilidade é um mecanismo fundamental nesses ambientes, pois é responsável por garantir a capacidade de comunicação entre os repositórios, tornando "[...] possível a pesquisa em simultâneo com significados partilhados nos vários repositórios, bem como a relação automática entre os resultados dessas pesquisas" (BAPTISTA, 2010, p. 72).

A fim de garantir confiabilidade, promover a cultura de partilha, maior acesso e melhor visibilidade dos dados de pesquisa, a German Research Foundation (DFG) e parceiros, em 2012, criaram um diretório para registro global dos Repositórios de Dados que armazenam dados de diferentes disciplinas acadêmicas espalhadas pelo mundo, o Re3data - Registry Of Research Data Repositories (re3data.org).

O uso do diretório é recomendado pela Comissão Europeia no Movimento Horizonte 2020 que financia pesquisas mundialmente e é outra iniciativa relacionada ao movimento "Open Access". Trata-se de uma ferramenta importante para que as instituições verifiquem quais repositórios são mais apropriados para acolher seus dados. Além disso, o diretório armazena "[...] informações sobre os repositórios em operação, permitindo que eles sejam mais facilmente localizados pelas comunidades interessadas, e dessa forma dando mais visibilidade aos resultados da sua pesquisa." (SAYÃO; SALES, 2015, p. 50).

Iniciativas como essa fortalecem o movimento cultural de partilha de dados, que precisa ser aceito no âmbito da comunicação científica. Além disso, foi necessária a criação de leis e imposição de obrigatoriedade das instituições de fomento para que dessem atenção à problemática de divulgação dos dados de pesquisas financiados com dinheiro público. Infelizmente ainda há um longo 
caminho para que essa cultura se torne natural na comunidade acadêmica.

Na próxima seção são apresentados os conceitos de El e seus atributos, que são responsáveis por auxiliar e contribuir no projeto e na avaliação de ambientes informacionais digitais como os Repositórios de Dados.

\section{ENCONTRABILIDADE DA INFORMAÇÃO}

Para Vechiato e Vidotti (2014, p. 164), a Encontrabilidade da Informação "[...] sustenta-se fundamentalmente na interseção entre as funcionalidades de um ambiente informacional e as características dos sujeitos informacionais." Nesse sentido, a El considera a Intencionalidade do sujeito informacional um fator importante para o projeto de um ambiente informacional digital.

O termo Findability (MORVILLE, 2005a) deu origem aos estudos relacionados à Encontrabilidade da Informação (VECHIATO; VIDOTTI, 2014). $\mathrm{O}$ termo original aparece ligado à Arquitetura da Informação (AI) sendo ela a solução para a problemática de Findablity nos ambientes informacionais digitais. Seu conceito está relacionado a dois fatores: navegação e recuperação. Assim, a Encontrabilidade vai além da Recuperação da Informação, pois abarca conceitos de navegação e o ideal de apropriação da informação para gerar conhecimento.

Rosenfeld, Morville e Arango (2015, p. 24, tradução nossa) apresentam quatro conceitos para Arquitetura da Informação, sendo que a encontrabilidade é considerada em um deles:

1. O desenho estrutural de ambientes informacionais compartilhados;

2. A combinação de sistemas de organização, rotulagem, busca e navegação no âmbito de ecossistemas físicos, digitais e cross-channel;

3. A arte e ciência de estruturar produtos de informação e experiências que permitam usabilidade, encontrabilidade e compreensão;

4. Uma disciplina emergente e comunidade de prática focada em trazer princípios de desenho e arquitetura para o ambiente digital (ROSENFELD; MORVILLE; ARANGO, 2015, p. 24).

Inf. Inf., Londrina, v. 24, n. 1, p. 51 - 79, jan./abr. 2019. 
Em um ambiente informacional digital os desenvolvedores devem se preocupar com a organização, a representação, a recuperação e a encontrabilidade da informação, viabilizando a apropriação da informação pelo sujeito informacional. Nesse sentido Morville (2005a) acredita que para a otimização da El três pontos devem ser levados em consideração:

a) Qualidade em ser localizável ou navegável;

b) Grau em que um objeto em particular pode ser de fácil descoberta ou localização;

c) Grau em que um sistema ou ambiente suportam a navegação e recuperação (MORVILLE, 2005a, p. 4, tradução nossa).

Nota-se que há duas perspectivas para que aconteça a Encontrabilidade dentro de qualquer ambiente informacional digital, podendo ocorrer "[...] a partir da busca prévia de informação por meio da navegação ou de estratégias de pesquisa em um mecanismo de busca (Search Engine), as quais, em um primeiro momento, são realizadas via palavras-chave" (VECHIATO; VIDOTTI, 2014 , p. 110, grifo nosso). Os mecanismos podem apresentar duas possibilidades para pesquisa, sendo eles: a busca simples e a busca avançada com utilização dos operadores booleanos.

Por meio dessas duas perspectivas para a obtenção de resultados devemos levar em consideração a grande diferença de que o "[...] ato de buscar não presume o encontro da informação" (LANDSHOFF, 2011, p. 17). A experiência de navegação ou até mesmo a busca por palavras-chave pode trazer resultados que podem confundir o sujeito informacional causando desconforto naquela situação.

O processo de busca de informação pode trazer um sentimento de frustração, entretanto, a El ocasiona satisfação ao usuário, trazendo ao mesmo a experiência positiva de buscar algo ou alguma coisa, um sentimento de satisfação e reconhecimento, o que acarreta consequentemente em sua produtividade, apropriação e geração de conhecimento (LANDSHOFF, 2011).

Para que a apropriação da informação aconteça, é importante que o conteúdo de qualquer ambiente informacional digital esteja efetivamente representado. Para descrição de recursos informacionais se faz uso de metadados, os quais "[...] são dados que descrevem, neste caso, as páginas 
web, os recursos informacionais contemplados e as ligações entre eles, visando atribuir significado" (VECHIATO; VIDOTTI, 2014, p. 71).

Sendo resultantes da organização e da representação da informação, os metadados são descritos em um banco de dados, influenciando diretamente a El na visualização via interface e por meio dos mecanismos de busca (LANDSHOFF, 2011; VECHIATO, VIDOTTI, 2014).

Nesse sentido, para Santos (2013, p. 8), uma "[...] mesma forma de representação pode não satisfazer os desejos de todos os usuários, podendo ser útil para um indivíduo, mas não para outro", sendo assim, para que aconteça a atribuição de significado a fim de garantir a qualidade na busca de informações é fundamental a presença dos metadados tanto na entrada de dados nos repositórios como na saída por meio da pesquisa realizada pelo sujeito informacional, levando em consideração suas necessidades informacionais.

Os metadados são um dos principais Atributos da Encontrabilidade da Informação (AEI), propostos por Vechiato e Vidotti (2014) para auxiliar a El e atender as necessidades informacionais dos sujeitos para apropriação da informação em um ambiente. Os autores elaboraram um Modelo de Encontrabilidade da Informação (MEI) ${ }^{2}$ que serve de base para que qualquer ambiente informacional digital elaborado a partir de uma visão Top-Down e/ou Bottom-Up.

Os AEI são "sinalizações" ao longo da estrada necessária para garantir o sucesso da Encontrabilidade da Informação, principalmente na era digital em que vivemos e com o ambiente Web que nos permite encontrar qualquer coisa ou alguém a qualquer momento desde que exista Internet (MORVILLE, 2005b).

O Quadro 1 que segue apresenta os AEI e suas definições, a fim de contextualizá-los:

2 [...] O modelo de encontrabilidade da informação (MEI) pode ser aplicado em quaisquer sistemas, ambientes ou arquiteturas da informação, influenciados pelo contexto sociotécnico emergente, que alia a Intencionalidade dos sujeitos ao desenvolvimento tecnológico (VECHIATO; VIDOTTI, 2014, p. 172). 


\section{Quadro1 - Atributos da Encontrabilidade da Informação (AEI)}

\begin{tabular}{|c|c|}
\hline Atributo & Descrição \\
\hline $\begin{array}{l}\text { Taxonomias } \\
\text { Navegacionais }\end{array}$ & $\begin{array}{l}\text { Utilizadas em estruturas de organização top-down, se } \\
\text { referem à organização das categorias informacionais } \\
\text { com vistas a facilitar a navegação e a descoberta de } \\
\text { informações. Essas categorias, por exemplo, são } \\
\text { organizadas geralmente em menus ou no corpo das } \\
\text { páginas Web, nas comunidades e coleções de } \\
\text { repositórios ou nas legendas utilizadas para } \\
\text { descrição dos assuntos nas estantes das bibliotecas, } \\
\text { organizadas previamente a partir de um sistema de } \\
\text { classificação. Conforme Aquino, Carlan e Brascher } \\
\text { (2009), as taxonomias navegacionais devem ser } \\
\text { apoiadas nos seguintes aspectos: categorização } \\
\text { coerente dos assuntos em relação ao entendimento } \\
\text { dos sujeitos; controle terminológico para redução de } \\
\text { ambiguidade; relacionamento hierárquico entre os } \\
\text { termos; e multidimensionalidade, possibilitando que } \\
\text { um termo possa ser associado a mais de uma } \\
\text { categoria de acordo com o contexto de uso. }\end{array}$ \\
\hline $\begin{array}{l}\text { Instrumentos de controles } \\
\text { terminológicos }\end{array}$ & $\begin{array}{l}\text { Compreendem os vocabulários controlados, como os } \\
\text { tesauros e as ontologias, para apoiar a } \\
\text { representação dos recursos informacionais. }\end{array}$ \\
\hline Folksonomias & $\begin{array}{l}\text { Estão relacionadas à organização social da } \\
\text { informação e propiciam ao sujeito a classificação de } \\
\text { recursos informacionais, bem como encontrar a } \\
\text { informação por meio da navegação (uma nuvem de } \\
\text { tags, por exemplo) ou dos mecanismos de busca, } \\
\text { ampliando as possibilidades de acesso. São } \\
\text { utilizadas em estruturas de organização bottom-up. } \\
\text { Quando associadas aos vocabulários controlados e } \\
\text { às tecnologias semânticas, potencializam as } \\
\text { possibilidades de encontrabilidade da informação. }\end{array}$ \\
\hline Metadados & $\begin{array}{l}\text { Compreendem a representação dos recursos } \\
\text { informacionais e são armazenados em banco de } \\
\text { dados para fins de recuperação da informação. }\end{array}$ \\
\hline Mediação dos informáticos & $\begin{array}{l}\text { Está associada ao desenvolvimento de sistemas, } \\
\text { dispositivos, bancos de dados e interfaces com } \\
\text { utilização de linguagens computacionais, com vistas } \\
\text { à gestão e à recuperação da informação. }\end{array}$ \\
\hline $\begin{array}{c}\text { Mediação dos profissionais } \\
\text { da informação }\end{array}$ & $\begin{array}{l}\text { Ocorre em ambientes informacionais em que há } \\
\text { sujeitos institucionais envolvidos na seleção, } \\
\text { estruturação e disseminação da informação. }\end{array}$ \\
\hline $\begin{array}{l}\text { Mediação dos sujeitos } \\
\text { informacionais }\end{array}$ & $\begin{array}{l}\text { Está relacionada às ações infocomunicacionais que } \\
\text { os sujeitos informacionais empreendem em } \\
\text { quaisquer sistemas e ambientes informacionais, por } \\
\text { exemplo, no que diz respeito à produção e à } \\
\text { organização da informação e do conhecimento em } \\
\text { ambientes colaborativos, gerados a partir de seus } \\
\text { conhecimentos, comportamento e competências que }\end{array}$ \\
\hline
\end{tabular}




\begin{tabular}{|c|c|}
\hline & caracterizam sua Intencionalidade. \\
\hline Affordances & $\begin{array}{l}\text { Funcionam como incentivos e pistas que os objetos } \\
\text { possuem e proporcionam aos sujeitos a realização de } \\
\text { determinadas ações na interface do ambiente. Essas } \\
\text { ações estão relacionadas à orientação, localização, } \\
\text { encontrabilidade, acesso, descoberta de informações } \\
\text { entre outras. }\end{array}$ \\
\hline Wayfinding & $\begin{array}{l}\text { Associado a orientação espacial, utilizando-se de } \\
\text { aspectos que facilitem a localização, a } \\
\text { encontrabilidade e a descoberta de informações por } \\
\text { meio da navegação na interface do ambiente. }\end{array}$ \\
\hline Descoberta de informações & $\begin{array}{l}\text { Está condicionada aos demais atributos de } \\
\text { encontrabilidade da informação no que diz respeito } \\
\text { às facilidades que a interface (navegação e/ou } \\
\text { mecanismos de busca) oferece para encontrar a } \\
\text { informação adequada às necessidades } \\
\text { informacionais do sujeito, bem como a possíveis } \\
\text { necessidades informacionais de segundo plano. }\end{array}$ \\
\hline $\begin{array}{l}\text { Acessibilidade e } \\
\text { Usabilidade }\end{array}$ & $\begin{array}{l}\text { Relacionados à capacidade do sistema permitir o } \\
\text { acesso equitativo à informação (acessibilidade) no } \\
\text { âmbito do público-alvo estabelecido em um projeto } \\
\text { com facilidades inerentes ao uso da interface } \\
\text { (usabilidade). }\end{array}$ \\
\hline Intencionalidade & $\begin{array}{l}\text { A teoria da Intencionalidade fundamenta a } \\
\text { importância em se enfatizar as experiências e } \\
\text { habilidades dos sujeitos informacionais no projeto de } \\
\text { ambientes e sistemas de informação. }\end{array}$ \\
\hline $\begin{array}{c}\text { Mobilidade, Convergência e } \\
\text { Ubiquidade }\end{array}$ & $\begin{array}{l}\text { Estão associados ao meio ambiente, externo aos } \\
\text { sistemas e ambientes informacionais, mas que os } \\
\text { incluem, dinamizando-os e potencializando as } \\
\text { possibilidades dos sujeitos em encontrar a } \\
\text { informação por meio de diferentes dispositivos e em } \\
\text { diferentes contextos e situações. }\end{array}$ \\
\hline
\end{tabular}

Fonte: (VECHIATO; OLIVEIRA; VIDOTTI, 2016, p. 7).

Assim, podemos destacar que o uso dessas ferramentas em conjunto aos demais recursos encontrados no conceito de $\mathrm{El}$ podem garantir que o ambiente informacional desenvolvido atenda às necessidades informacionais dos usuários de maneira satisfatória.

\section{RESULTADO E DICUSSÕES}

Fundamentados nos procedimentos metodológicos são apresentados nesta seção os resultados da análise realizada no Repositório de Dados 
denominado DataONE ${ }^{3}$ cuja área do conhecimento é de domínio da ciência da Terra. O ambiente é um compilado de repositórios do mesmo domínio de conhecimento, e nele são armazenadas pesquisas de âmbito mundial. Nele estão reunidos alguns ambientes informacionais dos centros de pesquisa e instituições educacionais que fazem parte do que eles chamam de "Member Node" - os dados científicos estão armazenados nesse repositório geral, facilitando a encontrabilidade das informações por essa comunidade cujas pesquisas estão relacionadas.

A Figura 2 que segue apresenta a Interface do Repositório de Dados DataONE.

\section{Figura 2 - Interface do DataONE}

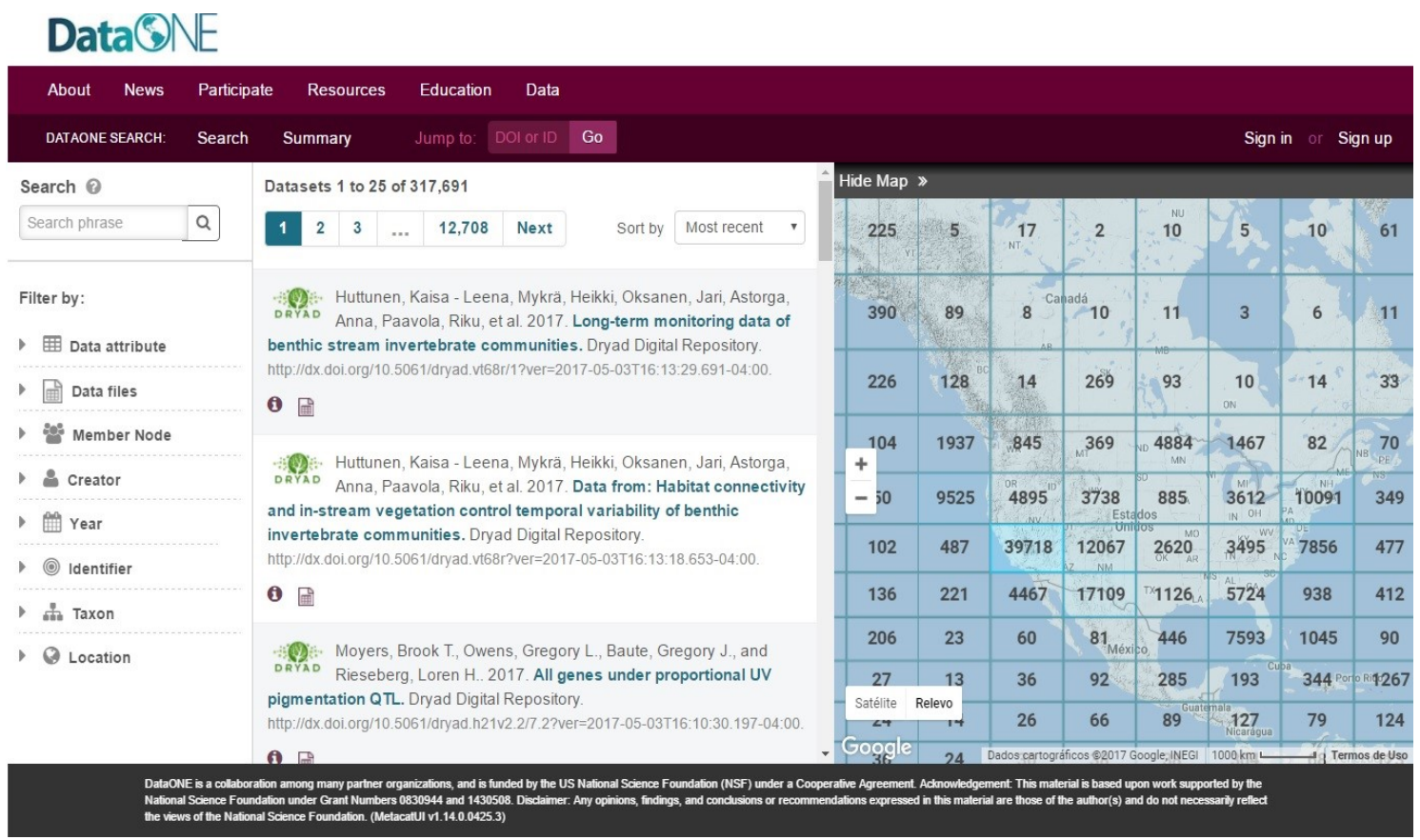

Fonte: Repositório de Dados DataONE.

Disponível em: https://search.dataone.org/\#data

Para análise do DataONE foi utilizado como instrumento de avaliação o "Checklist para avaliação de ambientes informacionais digitais híbridos" desenvolvido por Vechiato, Oliveira e Vidotti (2016), tendo sido adaptado para este trabalho para contemplar apenas os atributos de encontrabilidade da

\footnotetext{
${ }^{3}$ https://search.dataone.org/\#data
} 
informação, visto que o referido instrumento também possui outros atributos ligados à Arquitetura da Informação Pervasiva.

Antes dos resultados obtidos pelo Checklist, vale ressaltar que a plataforma DataONE não é encontrável facilmente. Tal ressalva é necessária, considerando que Morville (2005a) defende que a qualidade de encontro de um ambiente informacional via mecanismos de busca é tão importante quando a preocupação com a encontrabilidade dos recursos informacionais disponíveis dentro do ambiente.

Desse modo, para um usuário que não sabe da existência do DataONE ou fará a sua primeira visita partindo de uma busca pelo nome do repositório no Google, o primeiro resultado na página de resultados fará com que o sujeito encontre a página institucional geral do DataONE, e não a página inicial do repositório, dificultando o acesso rápido à interface de busca do repositório de dados. A seguir, a Figura 3 apresenta a página de resultados do Google.

\section{Figura 3 - Página de busca pelo Google}

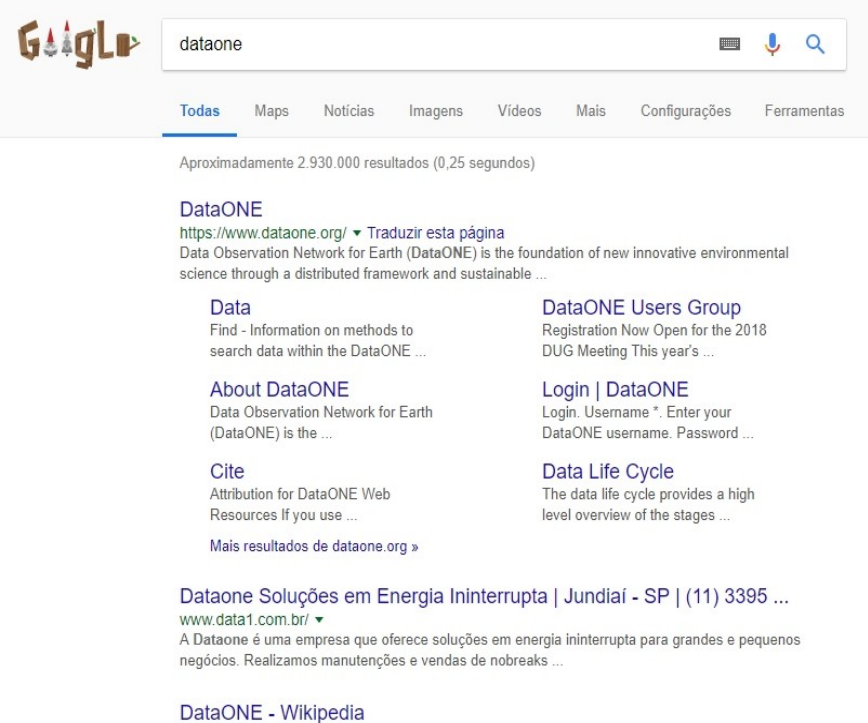

Fonte: Busca pelo ambiente DataONE.

Disponível em: https://bit.ly/2sPg4Kk

O primeiro link remete ao ambiente informacional digital geral da organização DataONE. Para chegar ao repositório de dados, é necessário o acesso a essa interface, desse modo a encontrabilidade do ambiente é prejudicada. Como podemos observar na Figura 3, nenhum dos três primeiros links direcionam o sujeito informacional a página inicial do repositório de dados 
de pesquisa.

Figura 4 - Página principal do ambiente DataONE

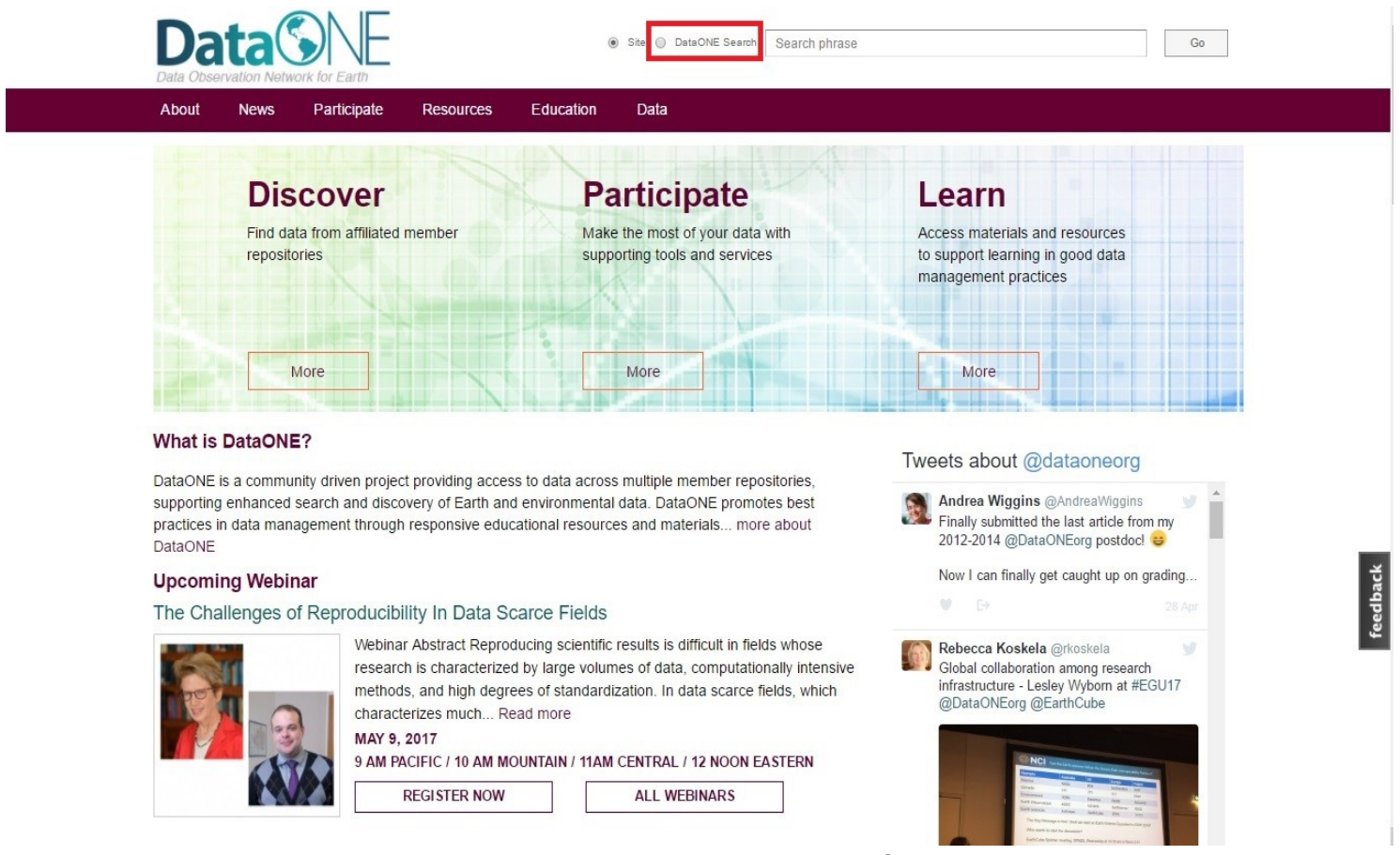

Fonte: Página inicial do DataONE.

Disponível em: https://www.dataone.org/

Nesse sentido, para que a encontrabilidade do ambiente seja de fato satisfatória, o link para o DataONE Search (como é chamado o Repositório de Dados) deveria estar melhor explicitado na plataforma principal ou com uma terminologia diferente nos resultados de busca pelo Google. Tal situação implica uma perda de tempo ao sujeito que está fazendo a busca pela primeira vez ou que não tenha conhecimento do repositório.

O Quadro 2 que segue apresenta os resultados da análise realizada por meio do Checklist. No decorrer da seção, são apontadas e exemplificadas as observações positivas e negativas advindas da avaliação. 


\section{Quadro 2 - Checklist de avaliação de ambientes digitais e híbridos - DataONE}

\begin{tabular}{|c|c|c|}
\hline Atributo & Checklist & $\begin{aligned} \text { - } & \text { SIM }(\mathbf{S}) \\
\text { - } & \text { NÃO (N) } \\
\text { - } & \text { PARCIALMENTE } \\
& \text { APLICÁVEL (P) } \\
\text { - } & \text { NÃO APLICÁVEL } \\
& \text { (NA) }\end{aligned}$ \\
\hline \multirow{2}{*}{$\begin{array}{l}\text { Taxonomias } \\
\text { navegacionais }\end{array}$} & $\begin{array}{c}\text { A taxonomia navegacional existente } \\
\text { possui categorização adequada dos } \\
\text { conceitos/termos. }\end{array}$ & $S$ \\
\hline & $\begin{array}{l}\text { A taxonomia navegacional existente } \\
\text { possui termos significativos e coerentes } \\
\text { que não dificultam seu entendimento. }\end{array}$ & $S$ \\
\hline $\begin{array}{l}\text { Instrumentos de } \\
\text { controle } \\
\text { terminológico }\end{array}$ & $\begin{array}{l}\text { São utilizados vocabulários controlados, } \\
\text { tesauros e/ou ontologias para a } \\
\text { representação do assunto dos recursos } \\
\text { informacionais. }\end{array}$ & $\mathrm{N}$ \\
\hline \multirow[b]{2}{*}{ Folksonomias } & $\begin{array}{l}\text { Há recursos de classificação social } \\
\text { (folksonomia) que favoreçam a } \\
\text { participação dos sujeitos informacionais. }\end{array}$ & $\mathrm{N}$ \\
\hline & $\begin{array}{l}\text { As tags geradas pelos sujeitos são } \\
\text { disponibilizadas em nuvem de tags } \\
\text { para facilitar a navegação social. }\end{array}$ & $\mathrm{N}$ \\
\hline \multirow[b]{2}{*}{ Metadados } & $\begin{array}{l}\text { Os recursos informacionais estão } \\
\text { representados por metadados. }\end{array}$ & $\mathrm{s}$ \\
\hline & $\begin{array}{l}\text { É utilizado padrão de metadados } \\
\text { coerente com a proposta do ambiente }\end{array}$ & S \\
\hline $\begin{array}{l}\text { Mediação dos } \\
\text { sujeitos } \\
\text { institucionais } \\
\text { (informáticos e } \\
\text { profissionais da } \\
\text { informação) }\end{array}$ & $\begin{array}{l}\text { O ambiente disponibiliza formas de } \\
\text { auxílio aos sujeitos informacionais a partir } \\
\text { de tutoriais (ambientes digitais). }\end{array}$ & $S$ \\
\hline \multirow{2}{*}{$\begin{array}{l}\text { Mediação dos } \\
\text { sujeitos } \\
\text { informacionais }\end{array}$} & $\begin{array}{l}\text { Os sujeitos participam da produção } \\
\text { da informação disponibilizada. }\end{array}$ & $S$ \\
\hline & $\begin{array}{l}\text { Os sujeitos participam da organização / } \\
\text { representação da informação }\end{array}$ & $\mathrm{s}$ \\
\hline Affordances & $\begin{array}{c}\text { As affordances aplicadas facilitam o } \\
\text { entendimento por diferentes tipos de } \\
\text { sujeitos informacionais. }\end{array}$ & $S$ \\
\hline Wayfinding & $\begin{array}{c}\text { O ambiente utiliza marcos e/ou } \\
\text { metáforas que dão pistas ao sujeito } \\
\text { para orientá-lo no espaço digital e/ou } \\
\text { analógico. }\end{array}$ & S \\
\hline
\end{tabular}

Inf. Inf., Londrina, v. 24, n. 1, p. 51 - 79, jan./abr. 2019. 


\begin{tabular}{|c|c|c|}
\hline \multirow{3}{*}{$\begin{array}{l}\text { Descoberta de } \\
\text { informações }\end{array}$} & $\begin{array}{l}\text { O mecanismo de busca utiliza o } \\
\text { recurso autocomplete ou } \\
\text { autossugestão. }\end{array}$ & $S$ \\
\hline & $\begin{array}{l}\text { Na página com os resultados de busca } \\
\text { são apresentadas facetas para o } \\
\text { refinamento da pesquisa. }\end{array}$ & $S$ \\
\hline & $\begin{array}{l}\text { Os resultados de busca apresentam } \\
\text { diversos tipos de documentos com } \\
\text { base na estratégia de busca inicial do } \\
\text { sujeito, apresentando-os de forma } \\
\text { relacionada. }\end{array}$ & $S$ \\
\hline \multirow{3}{*}{$\begin{array}{l}\text { Acessibilidade e } \\
\text { Usabilidade }\end{array}$} & O ambiente possui usabilidade. & S \\
\hline & $\begin{array}{l}\text { O ambiente digital possui recursos de } \\
\text { acessibilidade digital na interface. }\end{array}$ & N \\
\hline & $\begin{array}{l}\text { Foram utilizadas as } \\
\text { recomendações de acessibilidade } \\
\text { da W3C (WCAG 2.0). }\end{array}$ & $\mathrm{N}$ \\
\hline Intencionalidade & $\begin{array}{l}\text { Há indicativos de que a ecologia se } \\
\text { preocupa com a intencionalidade dos } \\
\text { sujeitos por meio de tecnologias como } \\
\text { análise de log de interação ou outras. }\end{array}$ & NA \\
\hline \multirow{3}{*}{$\begin{array}{l}\text { Mobilidade, } \\
\text { convergência e } \\
\text { ubiquidade }\end{array}$} & Possui interface responsiva. & $S$ \\
\hline & $\begin{array}{l}\text { Permite a continuidade das ações dos } \\
\text { sujeitos informacionais entre os } \\
\text { diferentes dispositivos. }\end{array}$ & NA \\
\hline & $\begin{array}{c}\text { As distintas partes da ecologia } \\
\text { informacional possuem consistência } \\
\text { entre si. }\end{array}$ & $S$ \\
\hline
\end{tabular}

Fonte: adaptado de (VECHIATO; OLIVEIRA; VIDOTTI, 2016, p. 15).

A avaliação do DataONE por meio do checklist foi realizada na página inicial do repositório de dados de pesquisa. Entretanto, para que a avaliação não fosse tão superficial, foi necessária a pesquisa na interface que reúne informações gerais da organização, já que a interface do DataONEsearch tratase de um ambiente destinado a busca e descoberta de informação. O checklist teve resultado positivo dada a quantidade de "S", que significa que o atributo está presente no ambiente. Entretanto, há problemas significativos referentes a encontrabilidade no repositório DataONE que serão descritos a seguir.

No que condiz ao atributo das Taxonomias Navegacionais a avaliação foi positiva, pois aparentemente a rotulagem utilizada é coerente e não é passível de ambiguidade. Nesse sentido, a navegação no ambiente é clara, assim como as possibilidades de recursos e ações possíveis para a pesquisa. 
As Figuras 5 e 6 demonstram as taxonomias utilizadas pelo repositório.

Figura 5 - Menu global horizontal do DataONE

\section{DataONE}

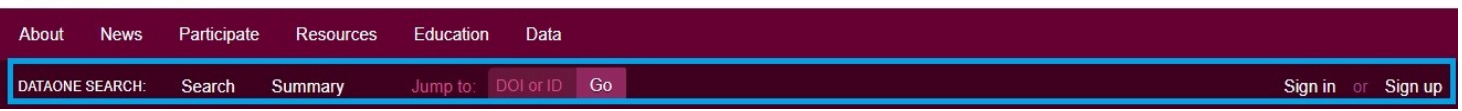

Fonte: Taxonomia Navegacional.

Disponível em: https://search.dataone.org/\#data

A figura 5 apresenta a taxonomia navegacional do menu global horizontal do repositório DataONE. Esse menu apresenta as possibilidades de pesquisa por DOI ou ID dos pesquisadores, e o local para login no repositório caso o visitante seja cadastrado. Além disso, a taxonomia "dataonesearch" está relacionada aos filtros abaixo, que trata-se apenas da rotulagem do menu global vertical do canto esquerdo da página, que apresentam os filtros para encontrabilidade no ambiente.

O segundo "search" representa a interface home do repositório. Caso o usuário vá para a página destinada ao "summary", por exemplo, clicando no campo "search", retorna-se à primeira página de pesquisa. Desse modo, mesmo com esta duplicidade, segundo a diretriz do checklist em que se avalia a coerência dos termos das taxonomias navegacionais, podemos declarar que não a incoerência, pois a navegação não é prejudicada. 
Figura 6 - Menu global vertical para refinamento de busca
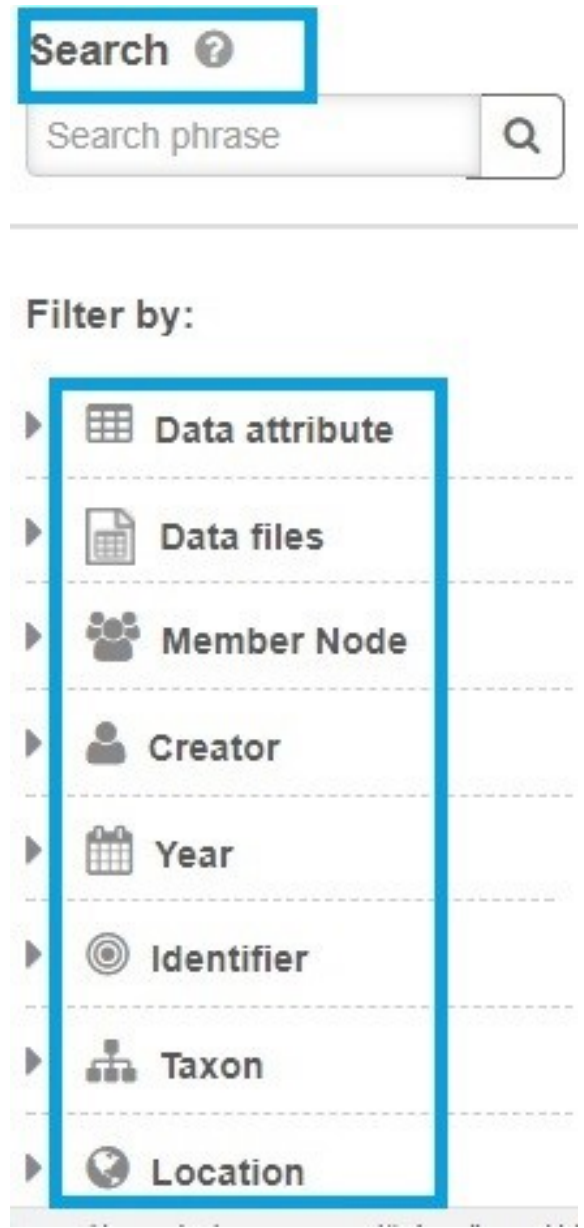

Fonte: Taxonomia Navegacional do DataONE.

Disponível em: https://search.dataone.org/\#data

Podemos notar a utilização de ícones em conjunto com as rotulagens das taxonomias navegacionais. Essa técnica geralmente facilita a compreensão da informação e o que elas representam no ambiente, a "estruturação das informações fica visível ao usuário final, pois o objetivo é que a descoberta das informações aconteça no momento da navegação. Conhecer o usuário nesse tipo de taxonomia é fundamental" (AQUINO; CARLAN; BRASCHER, 2009, p. 206).

O atributo referente ao Instrumento de Controle Terminológico não foi encontrado no ambiente, por isso a resposta foi não, pois a possibilidade de não ser aplicável nessa situação é muito difícil. Provavelmente a organização segue algum tipo de instrumento para a representação dos recursos informacionais do seu ambiente, principalmente se tratando de espaço voltado 
para a comunidade científica, entretanto não encontramos informações sobre esse recurso. Tal atributo se faz importante dentro de um ambiente informacional digital, pois:

[...] diz respeito à escolha dos termos adequados para representar os conceitos, de forma objetiva, evitando problemas como imprecisão e ambiguidade. Serão consideradas situações de sinonímia, polissemia, emprego de siglas, abreviaturas, e termos em outros idiomas, uma vez que podem comprometer a comunicabilidade das taxonomias. (AQUINO; CARLAN; BRASCHER, 2009, p. 207).

O atributo de Folksonomia não é utilizado pelo DataONE, pois não foram encontradas tags na interface principal do repositório nem na interface de resultado que apresentam os metadados descritivos da pesquisa e dos dados depositados. A Folksonomia pode ser compreendida como os "termos atribuídos pelos sujeitos permanecem atrelados à linguagem natural, o que interfere significativamente na recuperação e na encontrabilidade da informação (VECHIATO, 2013, p. 130). Segundo Wichowski (2009), existem métodos como, associação das tags com tesauros e ontologias para melhorias dessas e contribuição efetiva na organização, representação, recuperação e encontrabilidade da informação.

O repositório apresenta excelente qualidade no que diz respeito a um dos principais atributos de encontrabilidade que são os Metadados. Dessa forma, os metadados é resultante dos processos de:

[...] organização e representação da informação, os metadados, armazenados no sistema de gerenciamento de banco de dados, viabilizarão a encontrabilidade da informação via interface e mecanismos de busca. São utilizados em arquiteturas da informação top-down e bottom-up e podem ser aplicados em ambientes informacionais tradicionais, digitais e/ou híbridos (VECHIATO, VIDOTTI, 2014, p. 169).

O ambiente utiliza um padrão específico da comunidade científica das ciências da Terra, a Ecological Metadata Language (EML), desenvolvida pela Knowledge Network for Biocomplexity (KNB), que busca integrar dados de vários ambientes de coletas, laboratórios e pesquisadores.

Esses metadados são criados por meio do software gratuito Morpho, que permite, por meio de manuais de auxílio, a criação de metadados referentes as pesquisas desenvolvidas pelos pesquisadores que irão depositar seus dados e 
sua pesquisa no repositório. Os metadados são extremamente importantes para a recuperação e encontrabilidade da informação, principalmente em ambientes informacionais como os repositórios de dados, onde as pesquisas acontecem em sua maioria por meio do mecanismo de busca.

Em relação ao atributo de Mediação dos sujeitos institucionais (informáticos e profissionais da informação), as informações obtidas sobre esse ponto foram retiradas da interface geral do DataONE. Nele foi possível encontrar informações e explicações sobre como funcionam as situações que envolvem os depósitos de dados de pesquisa, assim como os softwares utilizados para o desenvolvimento do repositório e de outros serviços da organização. Os textos encontrados são completos e permitem a compreensão e o papel dos sujeitos institucionais no ambiente informacional digital. Segundo Vechiato (2013), a mediação desses profissionais está atrelada a todos os processos informacionais em todos os ambientes e arquiteturas de um espaço digital.

A Mediação dos sujeitos informacionais foi avaliada como positiva, por conta da participação do sujeito informacional na realização de depósito dos dados de pesquisa no ambiente, além disso, o software utilizado pelo repositório, referente aos metadados (Morpho) quando pesquisado, trouxe resultados sobre a possibilidade de criação de metadados. Desse modo, acreditamos que aconteça essa mediação.

Segundo Morville e Sullenger (2010), os profissionais da informação e informáticos responsáveis pelo desenvolvimento do projeto de um ambiente informacional digital, devem ressaltar que cada sujeito informacional possui origens, percepções, comportamentos e habilidades que são diferentes, sendo necessário conhecer e compreender esses sujeitos como ponto de partida, desse modo, a mediação dos sujeitos pode de fato potencializar a encontrabilidade no ambiente.

As Affordances e o atributo de Wayfinding auxiliam 0 sujeito informacional com pistas e orientação espacial ao navegar no ambiente. Elas são utilizadas pelo sistema para que os sujeitos possam realizar certas ações e foram, portanto, encontradas no repositório avaliado. Definindo cada uma 
delas, as Affordances são:

[...] possibilidades de ação que o ambiente [ou objeto] oferece ao agente. Apesar de parecer uma definição simples, há características do conceito envolvidas nesta definição, que necessitam ser destacadas. Uma delas está baseada na idéia de que durante a interação com o ambiente, o agente percebe as possibilidades de ação e não as qualidades do ambiente. Além disso, a captação de tais possibilidades depende da escala corporal e das capacidades de ação do agente." (OLIVEIRA, 2005, p. 90-91).

Já o Wayfinding está ligado a orientação espacial dentro dos ambientes informacionais digitais, segundo Morville (2005a), é um processo de cinco etapas que começa por saber onde está, conhecer seu destino e seguir a melhor rota para alcançá-lo, com a capacidade de reconhecer seu destino e por fim ter condições de encontrar seu caminho de volta ao ponto inicial. Ambos os atributos estão diretamente ligados a descoberta de informação por navegação.

No repositório DataONE foram encontrados recursos como: a mudança da seta do mouse para "mão" quando forem links, mudança de cores ao passar o mouse, setas nos filtros, indicando que há mais informações sobre o item, trilha de navegação na parte superior da interface, menus globais para que o sujeito esteja sempre bem orientado ao navegar no ambiente obtendo a possibilidade de ir e vir entre as páginas quando necessário, são alguns dos exemplos de recursos aplicáveis nesses atributos e que foram encontrados no repositório.

A Descoberta de informações segundo Vechiato (2013), refere-se aos recursos que busquem facilitar tanto pela navegação quanto no mecanismo de busca a encontrabilidade de informações que os sujeitos informacionais procuram no ambiente. Nesse checklist a avaliação foi positiva, pois o repositório utiliza em seu mecanismo de busca os recursos de autossugestão e refinamento de busca a partir da utilização de alguns filtros localizados na interface como um menu global. A seguir, as Figuras 7 e 8 representam os recursos enriquecedores do atributo de descoberta de informações. 


\section{Figura 7 - Recurso de autossugestão do mecanismo de busca}

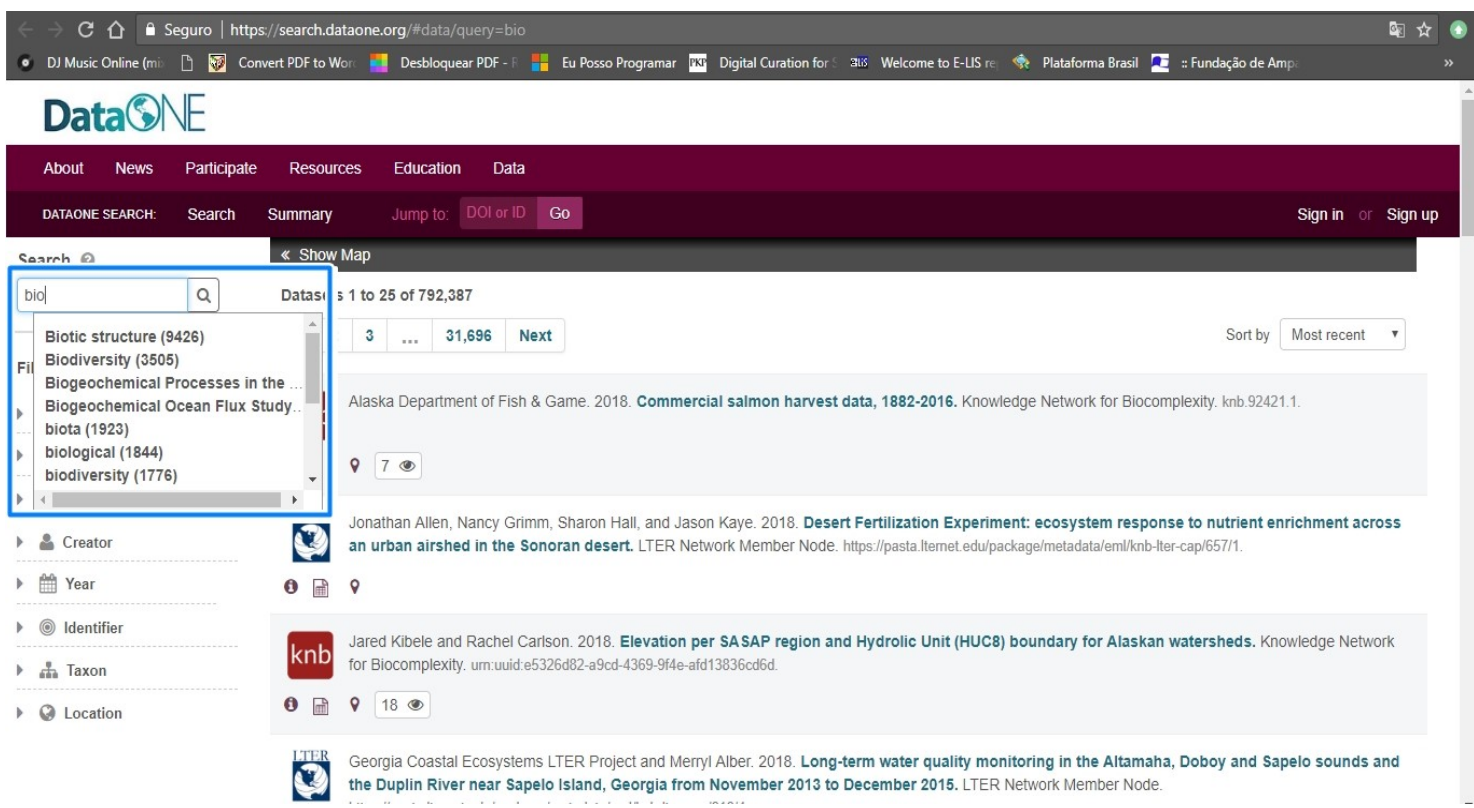

Fonte: Recurso de autossugestão do mecanismo de busca do DataONE.

Disponível em: https://search.dataone.org/\#data/query=bio

\section{Figura 8 - Refinadores de busca}

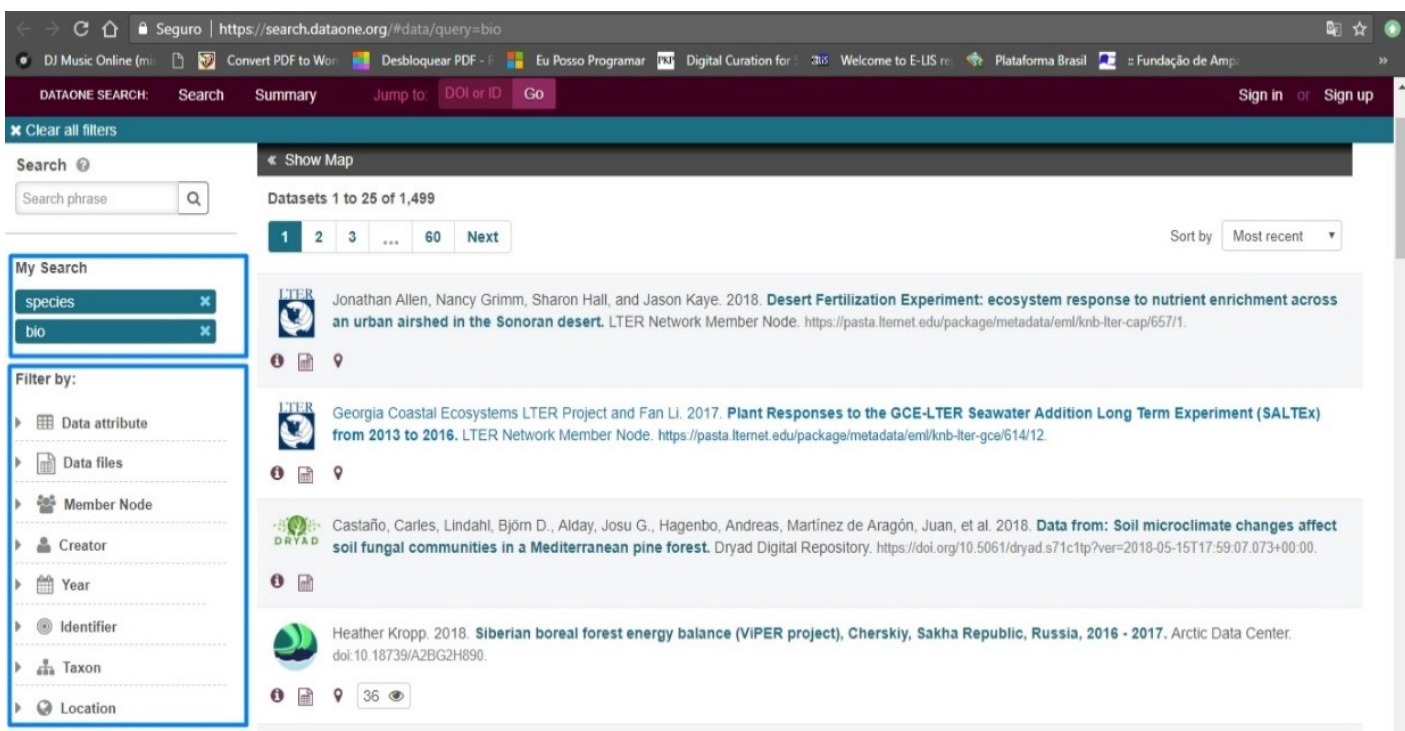

Fonte: Refinadores de busca do DataONE.

Disponível em: https://search.dataone.org/\#data/query=bio

Em relação ao atributo de Acessibilidade e Usabilidade, Vechiato (2013, p. 178) ressalta que:

[...] considerar que a dificuldade de acesso e de uso tanto pode prejudicar a encontrabilidade a priori, ou seja, quando impossibilita a descoberta de informações por meio da

Inf. Inf., Londrina, v. 24, n. 1, p. 51 - 79, jan./abr. 2019. 
navegação, quanto a posteriori, quando o sujeito já encontrou a informação num mecanismo de busca, mas não consegue acessá-la e usá-la a contento.

Desse modo, esses atributos são de extrema relevância nos ambientes informacionais digitais, a avaliação no DataONE foi negativa no que compete a Acessibilidade, pois o ambiente não atende as iniciativas de acessibilidade da World Wide Web Consortium (W3C), principal organização para padronização do ambiente Web, com ênfase na Web Accessibility Initiative (WAI). A ausência de recursos e elementos de acessibilidade digital pode segregar grupos de pesquisadores.

Encontrou-se como problemática a ausência da possibilidade de mudança de idioma. O ambiente é todo descrito em inglês. Não há possibilidade de aumento e diminuição de contraste ou de tamanho de fonte. Nesse contexto, o validador de nível de acessibilidade AccessMonitor apresentou a nota 6.4 para o DataONE, não passando no nível de prioridade "A" de avaliação do mesmo, sendo relatados erros e avisos significativos. Tal avaliação foi realizada com base na recomendação WCAG 2.0.

O sujeito informacional faz uso de sua Intencionalidade, que é um atributo de El, no ato de encontrar a informação desejada e adequada para o seu contexto de pesquisa, acarretando em uma experiência satisfatória e promovendo a visibilidade da informação e o registro da experiência, background, rede, estados de consciência (direcionalidade) (MIRANDA, 2010). $\mathrm{Na}$ avaliação no DataONE tal atributo foi considerado não aplicável pela avaliação pois, não há informações sobre análises de logs referentes aos sujeitos. Nota-se que há análises de dados baixados e acessos, entretanto, no que se refere a preocupação com o sujeito informacional e sua participação efetiva na organização e representação da interface do ambiente como um todo não se pode afirmar.

Sobre o atributo Mobilidade, Convergência e Ubiquidade, segundo Fumero (2007), tanto a ubiquidade, quanto a mobilidade dão forças para a convergência, principalmente pelo aumento de possibilidades de acesso a internet, estando atrelada ao crescimento das tecnologias móveis.

Essa avaliação foi realizada apenas no que condiz a interface home do 
repositório de dados DataONE. Nesse sentido, a questão da Responsividade foi considerada positiva, o que de fato é um atributo importante em relação ao uso do repositório pelos sujeitos informacionais. Atualmente se faz necessário que os ambientes informacionais digitais possam ser acessados sem barreira de tempo e espaço e em diferentes tipos de dispositivos.

Sob a ótica da Encontrabilidade da Informação, podemos destacar que o uso das diretrizes avaliadas no checklist, voltadas aos atributos de $\mathrm{El}$, atendem de forma positiva a encontrabilidade, como visto na avaliação descritiva acima, que destacam os recursos encontrados no DataONE.

Os atributos fazem parte de um conceito amplo que busca potencializar a encontrabilidade em ambientes informacionais digitais de forma simples e rápida, otimizando o tempo dos sujeitos (pesquisadores ou não) no processo de atendimento de suas necessidades informacionais, seja por meio da navegação ou mecanismo de busca.

Como podemos observar, o DataONE destaca-se pelos recursos de descoberta de informação que potencializam seu mecanismo de busca, consequentemente, podemos avaliar de forma positiva a ação da El nesse ambiente. Ainda sobre o mecanismo de busca, os metadados são um destaque relevante na composição do ambiente, pois o desenvolvimento desses se faz a partir de metadado específico para a comunidade alvo. Esse atributo é um dos mais importantes no processo de encontrabilidade, pois é responsável pela recuperação de dados e informação de qualidade.

Diante desse fato, é importante lembrar que o grau de encontrabilidade dos objetos dentro do DataONE de fato foi satisfatória e os atributos e diretrizes tem papel fundamental para que isso aconteça, entretanto, o problema de encontrabilidade da página inicial do repositório de dados pode ser destacado como um problema relevante, visto que o sujeito poderá ter dificuldade de encontrá-la rapidamente.

Devemos ressaltar que a Encontrabilidade da Informação antecede a apropriação da informação, que é um processo de extrema importância para que a geração de conhecimento seja realizada dentro das comunidades acadêmicos-científicas. Nesse tipo de ambiente, em especial, a 
encontrabilidade da informação é de suma importância pois são encontrados dados brutos e informações de todo o processo da pesquisa, enriquecendo ainda mais os estudos, oferecendo oportunidades de novas hipóteses de pesquisa e evitando a duplicidade de dados.

\section{CONSIDERAÇÕES FINAIS}

Abordamos no decorrer desse texto duas temáticas que ainda estão em fase de consolidação dentro do cenário da Ciência da Informação que são a Encontrabilidade da Informação e os Repositórios de Dados.

A criação de ambientes informacionais digitais como o caso dos Repositórios de Dados é de suma importância para o enriquecimento de diversas áreas do conhecimento, pois a cultura de partilha de dados de pesquisa dentro da comunidade potencializa exponencialmente a criação de novas hipóteses de pesquisa, evita a duplicação de esforços e, além disso, traz transparência em relação a utilização dos recursos financeiros que foram investidos nas pesquisas.

Para que $\mathrm{o}$ ambiente funcione de maneira que possa atender as necessidades informacionais dos sujeitos, é necessário que aconteça estudos e aplicação dos atributos de Encontrabilidade da Informação. Nesse sentido, o instrumento de avaliação utilizado para avaliação de um repositório específico, no caso o DataONE Search, fez com que fosse possível analisar a aplicabilidade dos atributos de Encontrabilidade da Informação, a fim de potencializar o ambiente para a cultura de partilha de dados de pesquisa.

O repositório avaliado utiliza recursos que enriquecem os atributos de encontrabilidade. A utilização de um padrão de metadados como o EML que se refere a um público específico enriquece a comunidade que o mesmo representa, além da encontrabilidade de informações. Além disso, a utilização dos recursos utilizados para potencializar as pesquisas dos sujeitos tanto na navegação quanto por meio do mecanismo de busca afeta positivamente a descoberta de informação no ambiente. O DataONE ainda é responsivo, facilitando o acesso e uso do repositório em diferentes dispositivos móveis. 
Todavia, recursos como o atributo de Acessibilidade precisam ser implementados a fim de atender uma parcela maior de sujeitos informacionais que podem fazer uso dos dados de pesquisa ali depositados.

\section{REFERÊNCIAS}

AQUINO, I. J.; CARLAN, E.; BRASCHER, M. B. Princípios classificatórios para a construção de taxonomias. Pontodeacesso, Salvador, v. 3, n. 3, p. 196-215, dez. 2009. Disponível em:

http://www.portalseer.ufba.br/index.php/revistaici/article/view/3626/2744. Acesso em: 18 jun. 2018.

BAPTISTA, A. A. A falar nos entendemos: a interoperabilidade entre repositórios digitais. Repositórios institucionais: democratizando o acesso ao conhecimento. Salvador: EDUFBA, p. 71-90, 2010. Disponível em: http://hdl.handle.net/1822/11517. Acesso em: 03 ago. 2017.

FUMERO, A. M. Contexto sociotécnico. In: FUMERO, A.; ROCA, G. Redes Web 2.0. Fundación Orange, 2007. p. 8-64. Disponível em: http://www.fundacionorange.es/areas/25_publicaciones/WEB_DEF_COMPLET O.pdf. Acesso em: 18 jun. 2018.

KIM, Y.; ZHANG, P. Understanding data sharing behaviors of STEM researchers: The roles of attitudes, norms, and data repositories. Library \& Information Science Research, v. 37, n. 3, p. 189-200, 2015. Disponível em: http://www.sciencedirect.com/science/article/pii/S0740818815000584. Acesso em: 02 ago. 2017.

LANDSHOFF, R. Findability: elementos essenciais para as formas de encontro da informação em bibliotecas digitais. 2011. 130 f. Dissertação (Mestrado em Mídias Digitais) - Pontifícia Universidade Católica de São Paulo, São Paulo, 2011. Disponível em: https://tede2.pucsp.br/handle/handle/18089. Acesso em: 05 ago. 2017.

MIRANDA, M. K. F. de O. O acesso à informação no paradigma póscustodial: da aplicação da intencionalidade para findability. 2010. 353 f. Tese (Doutorado em Informação e Comunicação em Plataformas Digitais) Universidade do Porto, Faculdade de Letras, Porto, 2010. Disponível em: http://repositorioaberto.up.pt/bitstream/10216/50422/2/tesedoutmajorymiranda0 00112543.pdf. Acesso em: 18 jun. 2018.

MONTEIRO, E. C. S. A; SANT'ANA, R. C. G. Repositórios de Dados Científicos nas Universidades Brasileiras e Portuguesas. In: Seminário em Ciência da Informação (SECIN), 6., 2016, Londrina. Anais eletrônicos... Londrina: UEL, 2016. p.166-174. Disponível 
em:http://www.uel.br/eventos/cinf/index.php/secin2016/secin2016/paper/viewFil e/338/166. Acesso em: 03 ago. 2017.

MORVILLE, P. Ambient findability. Sebastopol: O'Really, 2005a.

MORVILLE, P. Libraries at the crossroads of ubiquitous computing and the internet. Online, v. 29, n. 6, nov./dez. 2005b. Disponível em:

http://www.infotoday.com/online/nov05/morville.shtml. Acesso em: 05 ago. 2017.

MORVILLE, P.; SULLENGER, P. Ambient findability: libraries, serials, and the internet of things. The serials librarian, v. 58, n. 1-4, p. 33-38, 2010.

OLIVEIRA, F. I. da S. Affordances: a relação entre agente e ambiente. 2005. 99 f. Dissertação (Mestrado em Filosofia) - Universidade Estadual Paulista, Faculdade de Filosofia e Ciências, Marília, 2005. Disponível em: https://repositorio.unesp.br/bitstream/handle/11449/88194/oliveira_fis_me_ma.p df?sequence=1\&isAllowed=y. Acesso em: 03 ago. 2017.

ROSENFELD, L.; MORVILLE, P.; ARANGO, J. Information Architecture: for the Web and beyond. 4. ed. Sebastopol, CA: O'Reilly, 2015.

SALINAS, D. T.; MARTÍN, A. M.; GUTIÉRREZ, E. F. Analysis of the Coverage of the Data Citation Index - Thomson Reuters: disciplines, document types and repositories. Revista Española de Documentación Científica, v. 37, n. 1, p. 9-6, 2014. Disponível em: http://dx.doi.org/10.3989/redc.2014.1.1114. Acesso em: 03 ago. 2017.

SANTOS, P. L. V. A. C. Catalogação, formas de representação e construções mentais. Tendências da Pesquisa Brasileira em Ciência da Informação, v. 6, n. 1, p. 1-24, 2013. Disponível em: http://hdl.handle.net/11449/115044. Acesso em: 06 ago. 2017.

SAYÃO, L. F.; SALES, L. F. Guia de Gestão de Dados de Pesquisa para Bibliotecários e Pesquisadores. Rio de Janeiro: CNEN/IEN, 2015. Disponível em:

http://www.cnen.gov.br/images/CIN/PDFs/GUIA_DE_DADOS_DE_PESQUISA. pdf. Acesso em: 02 ago. 2017.

TOLLE, K.; TANSLEY, S.; HEY, T. Jim Gray e a eScience: um método científico transformado. In: HEY, T.; STEWARD, T.; TOLLE, K. (Orgs.). 0 quarto paradigma: descobertas científicas na era da eSience. São Paulo: Oficina de textos, 2011. p. 17-29.

VECHIATO, F. L. Encontrabilidade da informação: contributo para uma conceituação no campo da Ciência da Informação. 2013. 206 f. Tese (Doutorado em Ciência da Informação) - Universidade Estadual Paulista, Faculdade de Filosofia e Ciências, Marília, 2013. Disponível em: http://hdl.handle.net/11449/103365. Acesso em: 18 jun. 2018. 
VECHIATO, F. L; VIDOTTI, S. A. B. G. Encontrabilidade da informação. São Paulo: Cultura Acadêmica, 2014. (Coleção PROPG Digital-UNESP). Disponível em: http://hdl.handle.net/11449/126218. Acesso em: 05 ago. 2017.

VECHIATO, F. L; OLIVEIRA, H. P.; VIDOTTI, S. A. B. G. Arquitetura da Informação Pervasiva e Encontrabilidade da Informação: Instrumento para a avaliação de ambientes informacionais híbridos. In: Encontra Nacional de Pesquisa em Ciência da Informação (ENANCIB), 17., 2016, Salvador. Anais eletrônicos... Salvador: UFBA. p. 3768-3787. Disponível em: http://www.ufpb.br/evento/ti/ocs/index.php/enancib2016/enancib2016/paper/vie wFile/4118/2571. Acesso em: 01 ago. 2017.

WICHOWSKI, A. Survival of the fittest tag: folksonomies, findability, and the evolution of information organization. First monday: peer-reviewed journal on the internet, v. 14, n. 5, p. 1-12, 2009. Disponível em: http://firstmonday.org/ojs/index.php/fm/article/viewArticle/2447/2175. Acesso em: 18 jun. 2018.

\title{
THE FINDABILITY OF INFORMATION IN DATA REPOSITORIES: AN ANALYSIS OF DATAONE
}

\begin{abstract}
Introduction: The importance of the dissemination of research data has been increasingly debated by the scientific community in the context of Open Science, mainly to maximize the use and reuse of data from scientific research. Data Repositories aim at the storage, organization, dissemination, retrieval and preservation of research data, enhancing communication and scientific collaboration. Studies in the field of Information Science, especially Information Findability, bring significant contributions to the design and implementation of Data Repositories. Objectives: to analyze the DataONE data repository from the viewpoint of Information Findability. Methodology: the observation technique was used with the support of the evaluation tool checklist, which allows the analysis of informational environments from the attributes of Information Findability. Results: positive aspects include the use of specific metadata standards for the Earth Science community, the Ecological Metadata Language (EML), and the attribute of Responsiveness. As a negative aspect, we can notice the lack of Digital Accessibility resources. Conclusion: it is concluded that, in general, DataONE contemplates the main attributes of Information Findability, which facilitates the interaction and findability of data and information by informational subjects.
\end{abstract}

Descriptors: Findability of Information. Data Repositories. Scientific Data. DataONE.

\section{ENCONTRABILIDAD DE LA INFORMACIÓN EN REPOSITORIOS DE DATOS: UN ANÁLISIS DEL DATAONE}




\section{RESUMEN}

Introducción: la importancia de la diseminación de datos de investigación viene siendo cada vez más debatida por la comunidad científica en el contexto de la Ciencia Abierta, principalmente para maximizar el uso y el reuso de los datos provenientes de investigaciones científicas. Los repositorios de datos tienen como objetivo el almacenamiento, la organización, la diseminación, la recuperación y la preservación de datos de investigación, potenciando la comunicación y la colaboración científica. Los estudios del campo de la Ciencia de la Información, en especial la Encontrabilidad de la Información, traen contribuciones significativas para el proyecto y para la implementación de Repositorios de Datos. Objetivos: analizar el repositorio de datos DataONE bajo la óptica de la Encontrabilidad de la Información. Metodología: se utilizó la técnica de observación con apoyo del instrumento de evaluación checklist, que permite el análisis de ambientes informacionales a partir de los atributos de Encontrabilidad de la Información. Resultados: como aspectos positivos se destacan la utilización de patrón de metadatos específico para la comunidad de las Ciencias de la Tierra, el Ecological Metadata Language (EML), y el atributo de Responsabilidad. Como aspecto negativo, se nota la ausencia de recursos de Accesibilidad Digital. Conclusión: se concluye que, en general, el DataONE contempla los principales atributos de Encontrabilidad de la Información, lo que facilita la interacción y la constancia de los datos y de la información por los sujetos informacionales.

Descriptores: Encontrabilidad de la información. Repositorios de datos. Datos de búsqueda. DataONE. 